\title{
PENGEMBANGAN APLIKASI SMART TOUCH PRESENTER KIT UNTUK PRESENTASI INTERAKTIF
}

\author{
I Putu Eka Swastika ${ }^{1}$, I Gede Mahendra Darmawiguna ${ }^{2}$, \\ I Made Gede Sunarya ${ }^{3}$ \\ Jurusan Pendidikan Teknik Informatika \\ Universitas Pendidikan Ganesha \\ Singaraja, Bali \\ E-mail: iputuekaswastika@gmail.com ${ }^{1}$,igd.mahendra.d@gmail.com ${ }^{2}$, imadegedesunarya @gmail.com ${ }^{3}$
}

\begin{abstract}
Abstrak-Penggunaan perangkat seperti komputer tablet ataupun interactive whiteboard memanfaatkan teknologi layar sentuh dalam penyajian presentasi digital yang lebih interaktif terbukti memberikan dampak positif dibandingkan metode pembelajaran konvensional yang menggunakan papan tulis biasa. Dengan memanfaatkan perangkat wiimote yang merupakan remot kontrol untuk game console Nintendo Wii, wiimote library, LED inframerah serta bluetooth dapat dibuat teknologi yang menyerupai interactive whiteboard. Penelitian ini bertujuan untuk 1) Merancang aplikasi Smart Touch Presenter Kit untuk presentasi interaktif; 2) Mengimplementasikan rancangan sistem Smart Touch Presenter Kit untuk presentasi interaktif; 3) Membuat pena $L E D$ inframerah yang digunakan sebagai perangkat input aplikasi Smart Touch Presenter Kit; 4) Mengetahui pengaturan optimal untuk penggunaan perangkat wiimote untuk menghasilkan pendeteksian cahaya inframerah yang baik.

Aplikasi ini dikembangkan dengan menggunakan metode Waterfall dan diimplementasikan dalam bahasa pemrograman $C \#$ menggunakan editor Visual Studio. Dalam pengembangan aplikasi ini juga dikombinasikan dengan penggunaan wiimote library untuk keperluan pembacaan data dari perangkat wiimote. Aplikasi ini dapat dijalankan pada komputer dengan sistem operasi Windows yang mendukung .net framework.

Aplikasi ini memiliki tiga fitur utama yaitu 1) Smart Touch Presenter yang mengubah data koordinat inframerah menjadi kontrol kursor komputer; 2) Smart Note yang memberikan fitur untuk membuat catatan pada layar; 3) Magnifier yang dapat digunakan untuk memperbesar bagian tertentu pada layar agar dapat dilihat lebih jelas. Dengan adanya aplikasi ini diharapkan dapat membantu para pengguna dalam memberikan
\end{abstract}

presentasi atau penyajian materi agar lebih interaktif dengan biaya terjangkau.

Kata kunci - Solusi presentasi interaktif, Interactive whiteboard, Bluetooth, Wiimote, Smart presenter.

Abstract - The use of devices such as tablet computers or interactive whiteboards utilizing touchscreen technology in a presentation of more interactive digital presentations provide a positive impact in comparison to conventional learning methods that use a regular whiteboard. By utilizing the wiimote remote control for the Nintendo Wii game console, wiimote library, infrared LEDS and bluetooth a technology similar to interactive whiteboards can be develop. This study aims to 1) Design Smart Touch Presenter Kit application for interactive presentations; 2) Implement the system desing of Smart Touch Presenter Kit application for interactive presentations; 3) Make an infrared LED pen that is used as an input device for Smart Touch Presenter Kit application; 4) Determine the optimal settings for the use of the Wiimote to produce good detection of infrared light.

This application is developed using the Waterfall method and implemented in The $C$ \# programming language using the Visual Studio editor. In the development of this application is also combined with the use of the wiimote library for reading data from the wiimote. This application can be run on a computer with a Windows operating system that supports the .net framework.

This application has three main features: 1) Smart Touch presenter that transforms infrared coordinate data into a computer cursor control; 2) Smart Note that provide a feature to make notes on the screen; 3 ) Magnifier that can be used to enlarge a specific part on the screen so that it can be seen more clearly. The application is expected to help the users in delivering 
presentation to make it more interactive with affordable cost.

Keywords- Interactive presentation solution, Interactive whiteboard, Wiimote, Bluetooth, Smart presenters.

\section{PENDAHULUAN}

Indonesia Dewasa ini perkembangan teknologi tidak hanya bertujuan untuk membawa permasalahan yang ada pada kehidupan kita sehari-hari ke dalam bentuk komputasi pada komputer. Perkembangan teknologi sudah beranjak ke bagaimana manusia dapat berinteraksi langsung dengan informasi digital tersebut secara alami. Penemuan Dr. George Samuel Hurst pada tahun 1971 yaitu layar sentuh memberi perubahan yang sangat signifikan terhadap cara manusia berinteraksi dengan komputer atau data[1].

Dalam proses pembelajaran saat ini digunakan media presentasi digital dengan tujuan meningkatkan efisiensi waktu sehingga pengajar tidak menulis ulang materi yang telah disampaikan sebelumnya. Akan tetapi penggunaan media presentasi digital tentu memiliki beberapa kelemahan yang salah satunya tidak dapat mencantumkan semua materi dalam media presentasi karena akan mengakibatkan kebosanan siswa.

Dalam mengatasi permasalahan tersebut, penggunaan perangkat seperti komputer tablet ataupun interactive whiteboard dalam penyajian presentasi digital yang lebih interaktif terbukti memberikan dampak yang positif dibandingkan metode pembelajaran konvensional yang menggunakan papan tulis bias[3]. Akan tetapi untuk menyediakan perangkat seperti komputer tablet di sekolah, tentu saja memerlukan biaya yang sangat besar.

J. C. Lee (2008) menyebutkan bahwa teknologi yang menyerupai interactive whiteboard dapat dibuat memanfaatkan perangkat wiimote yang merupakan remot kontrol untuk game console Nintendo Wii, dengan menggunakan 2 buah LED inframerah yang letaknya statis wiimote dapat menentukan posisi koordinat (x, y). Dengan mengukur besar perputaran wiimote dan jarak antara wiimote dengan LED inframerah membuat pergerakan wiimote dapat menggerakkan kursor pada game console Nitendo Wii[2].

Dalam penelitiannya, Lee membalik cara kerja wiimote dengan membuat posisi wiimote tetap statis dan $L E D$ inframerah yang dibuat dapat bergerak secara dinamis, hasilnya pergerakan LED inframerah dapat membuat kursor bergerak. Pada implementasinya Lee memodifikasi LED inframerah dalam sebuah bentuk pena inframerah untuk memudahkan penggunaan.

S. N. Cheong et.al (2010) melakukan sebuah penelitian dengan judul "Wiimote-Based MultiTouch Tabletop To Improve Students' Learning Experience". Dalam penelitian mereka pengintegrasian komponen yang digunakan untuk membuat interactive whiteboard berbasis wiimote dimodifikasi dalam bentuk sebuah tabletop, yaitu sebuah meja yang dilengkapi dengan layar sentuh. Berdasarkan pengamatan penulis cara kerja dan fitur yang diberikan masih tetap sama[4].

Andre Yusdianto dik (2011) melakukan penelitian yang serupa mengacu pada penelitian $\mathrm{J}$. C. Lee. Mereka mengembangkan sebuah aplikasi interactive whiteboard dengan penambahan fitur drawing. Ini memungkinkan pengguna untuk menggambar pada permukaan whiteboard dengan menggunakan aplikasi interactive whiteboard tersebut[5].

Berdasarkan hasil penelitian tersebut, penulis ingin mengembangkan aplikasi smart presenter dengan nama Smart Touch Presenter Kit yang mampu mengubah suatu permukaan menjadi layar sentuh dengan berbagai fitur yang membantu dalam melakukan presentasi yaitu Smart Note (catatan) dan Magnifier (kaca pembesar). Tujuan penelitian ini adalah merancang dan mengimplementasikan rancangan dari aplikasi Smart Touch Presenter Kit, membuat pena LED inframerah sebagai alat input dan mencari pengaturan yang optimal dalam penggunaan perangkat wiimote untuk menghasilkan pendeteksian inframerah yang optimal. Fungsi kursor yang ada pada aplikasi ini hanya terbatas pada klik kanan dan kiri saja. Dengan dikembangkannya aplikasi ini diharapkan fapat membantu dalam menyediakan teknologi presentasi interaktif dengan biaya yang terjangkau.

\section{KAJIAN TEORI}

\section{A. Nitendo Wii}

Wii adalah konsol video game generasi ketujuh yang dibuat oleh Nintendo, dan pengganti konsol Nintendo sebelumnya, yaitu GameCube. Ini adalah konsol rumah Nintendo yang kelima. Konsol ini awalnya dirilis pada tanggal 19 November, 2006 di toko-toko Amerika, tak lama kemudian juga dirilis di negara lain, dan menjadi konsol terkemuka di Amerika Serikat, Eropa dan Jepang. Lebih dari 90 juta unit dikapalkan ke seluruh dunia, yang merupakan konsol rumahan Nintendo dengan penjualan terbaik, dan 3 besar terlaris sepanjang masa untuk konsol rumahan. 


\section{B. Wii Remote (Wiimote)}

Wii remote (lebih dikenal sebagai wiimote) adalah perangkat input utama Nitendo Wii. Perangkat nirkabel ini menggunakan teknologi bluetooth standar untuk berkomunikasi dengan Wii. Dibangun dengan chip bluetooth Broadcom $B C M$ 2042, dan berisi beberapa perangkat yang berfungsi sebagai penyedia data, serta port ekspansi untuk eksternal add-ons. Wii remote menggunakan protokol bluetooth HID (Human Interface Device) standar untuk berkomunikasi dengan host. Dengan demikian, wii remote dapat digunakan sebagai perangkat input standar untuk semua bluetooth host tanpa perlu melakukan otentikasi, pairing atau enkripsi dalam melakukan koneksi dengan perangkat lainnya. Tetapi wii remote juga dapat dihubungkan ke perangkat bluetooth lainya dalam mode pairing dengan demikian wiimote dapat langsung terhubung ke perangkat ketika terdeteksi.

Wiimote dilengkapi dengan microprocessor 805116 bit dan memori chip EEPROM $16 \mathrm{~KB}$ di mana bagian dari $6 \mathrm{~KB}$ dapat secara bebas dibaca dan ditulis oleh pengguna. Hal ini memudahkan untuk melakukan penyimpanan dan transportasi data. Beberapa hardware dan pengaturan kalibrasi perangkat lunak, serta pilihan antarmuka dapat disimpan dalam wiimote dalam mode ini dan dapat diakses di mana saja sesuai dengan kebutuhan pengguna [5].

\section{Bluetooth}

Bluetooth adalah sebuah teknologi komunikasi wireless (tanpa kabel) yang beroperasi dalam pita frekuensi $2,4 \mathrm{GHz}$ unlicensed ISM (Industrial, Scientific and Medical) dengan menggunakan sebuah frequency hopping tranceiver yang mampu menyediakan layanan komunikasi data dan suara secara real-time antara host-host bluetooth dengan jarak jangkauan layanan yang terbatas (sekitar 10 meter). Bluetooth sendiri dapat berupa card yang bentuk dan fungsinya hampir sama dengan card yang digunakan untuk wireless local area network (WLAN) di mana menggunakan frekuensi radio standar IEEE 802.11, hanya saja pada bluetooth mempunyai jangkauan jarak layanan yang lebih pendek dan kemampuan transfer data yang lebih rendah.

Pada dasarnya bluetooth diciptakan bukan hanya untuk menggantikan atau menghilangkan penggunaan kabel di dalam melakukan pertukaran informasi, tetapi juga mampu menawarkan fitur yang baik untuk teknologi mobile wireless dengan biaya yang relatif rendah, konsumsi daya yang rendah, interoperability yang menjanjikan, mudah dalam pengoperasian dan mampu menyediakan layanan yang bermacam-macam.

\section{Inframerah}

Infrared atau bahasa Indonesianya disebut inframerah merupakan sebuah radiasi elektromagnetik yang panjang gelombangnya lebih panjang dari cahaya tampak tetapi juga lebih pendek dari radiasi gelombang radio. Inframerah ini berasal dari bahasa latin alias merah yang merupakan warna dari cahaya tampak dari gelombang terpanjang, sedangkan infra berarti bawah. Inframerah ditemukan oleh Sir William Herschell, Seorang astronom kerajaan Inggris yang secara tidak sengaja ditemukan ketika William sedang melakukan penelitian untuk mencari bahan penyaring optik.

Radiasi elektromagnetik adalah kombinasi medan listrik dan medan magnet yang berosilasi, merambat lewat ruang dan membawa energi dari satu tempat ke tempat yang lain. Cahaya tampak adalah salah satu bentuk radiasi elektromagnetik.

\section{E. Wiimote Library}

Wiimote library adalah library pihak ketiga untuk mengelola interaksi dengan Nintendo Wii remote yang terhubung melalui bluetooth. Library membuka dua cara untuk berinteraksi dengan remot Wii:

1. Event driven - setiap kali ada perubahan state wii remote, event akan dijalankan.

2. Polling - Wii Remote dipertanyakan pada interval yang ditetapkan untuk keadaannya.

Pendekatan event driven akan memunculkan komplikasi yang tidak perlu karena cara kerja WiimoteLib built-in event hanya memantau perubahan state remot Wii. Perubahan state dijalankan setiap kali wii remote mendeteksi perubahan.

Pendekatan polling memastikan bahwa statestate wiimote disinkronisasi dan oleh sebab itu estimasi stereoscopic sumber inframerah mengajukan kesalahan sesedikit mungkin. Ketika menggunakan pendekatan polling, state-state wii remote diterima pada saat yang sama daripada mengambil catatan waktu saat event dijalankan.

\section{F. C\# dan Pemrograman .NET}

C\# adalah bahasa modern yang dibuat oleh Microsoft sebagai bagian dari bahasa .NET platform. .NET adalah lapisan perangkat lunak yang mempermudah kita untuk menulis program yang dapat berkomunikasi dengan sistem operasi (dalam hal ini, Windows). Seperti namanya, C\# berasal dari $C++$, tetapi setelah versi ke 3 telah berkembang teknik dan unsur-unsur yang membuatnya berbeda sendiri. Yang paling 
penting, C\# memiliki dukungan dari .NET Framework.

.NET Framework memungkinkan $C \#$ untuk beroperasi lancar dengan Windows, dan mengambil keuntungan dari fitur Windows yang sudah akrab pada kalangan pengguna di seluruh dunia. Kita juga dapat membuat aplikasi $C \#$ yang dapat kita gunakan di web, dalam banyak cara. $C \#$ mirip dengan $C++$ dan Java membuatnya mudah untuk belajar bagi programmer yang akrab dengan bahasa-bahasa tersebut, tetapi juga mudah dipelajari sebagai bahasa pertama kita.

\section{METODOLOGI}

\section{A. Analisis Masalah dan Solusi}

Kemajuan teknologi telah membuat perubahan yang sangat signifikan terhadap cara manusia berinteraksi dengan informasi digital. Touch screen adalah salah satu teknologi yang membuat kita dapat berinteraksi dengan data secara alami. Untuk membantu penyampaian materi atau presentasi agar lebih interaktif digunakan media presentasi digital, akan tetapi media ini masih memiliki kelemahan yaitu pemateri disarankan tidak mencantumkan keseluruhan materi dalam media presentasi karena akan mengakibatkan kebosanan.

Pada presentasi menggunakan media presentasi digital yang dicantumkan hanya materi pokoknya saja, kemudian pemateri bertugas untuk menjelaskan materi lebih lanjut. Dalam memberikan penjelasan penggunaan perangkat seperti komputer tablet ataupun interactive whiteboard untuk penyajian presentasi digital yang lebih interaktif terbukti memberikan dampak yang positif dibandingkan metode pembelajaran konvensional yang menggunakan papan tulis biasa [3]. Akan tetapi untuk menyediakan perangkat seperti komputer tablet di sekolah, tentu saja memerlukan biaya yang sangat besar.

Berdasarkan hal ini penulis ingin mengembangkan aplikasi Smart Touch Presenter Kit yang mampu mengubah suatu permukaan menjadi layar sentuh dengan memanfaatkan teknologi wiimote, wiimote library, LED inframerah dan juga bluetooth.

\section{B. Analisis Perangkat Lunak}

Pada tahap kedua yaitu analisis perangkat lunak yang pada model waterfall masuk ke dalam bagian dari System and software design (sistem dan desain perangkat lunak).

1 ) Kebutuhan Perangkat Lunak
Aplikasi Smart Touch Presenter Kit dirancang agar dapat mengimplementasikan proses-proses sebagai berikut.

1) Menampilkan jendela aplikasi yang terdiri dari jendela Smart Touch Presenter, jendela kalibrasi, jendela Smart Note dan jendela Magnifier/kaca pembesar.

2) Mendeteksi wiimote yang terhubung dan/atau menghubungkan ke komputer.

3) Mendeteksi perubahan state wii remote.

4) Mengubah data dari wiimote library menjadi kontrol kursor.

5) Menampilkan status baterai wiimote.

6) Menampikan banyaknya cahaya inframerah yang terdeteksi.

7) Mengubah kelembutan gerakan kursor.

8) Melakukan kalibrasi, menyimpan dan menampilkan hasilnya.

9) Membuat, menyimpan, dan membuka catatan.

10) Menuliskan, menghapus, memilih, mengubah ukuran dan mengubah warna callout (ink strokes) pada kanvas/layar.

11) Melakukan pembesaran pada layar, mengubah ukuran perbesaran, mengubah ukuran jendela Magnifier.

2) Tujuan Pengembangan Perangkat Lunak

Adapun tujuan pengembangan perangkat lunak adalah sebagai berikut.

1. Aplikasi dapat menampilkan jendela utama, jendela kalibrasi, jendela Smart Note dan jendela Magnifier/kaca pembesar.

2. Aplikasi dapat melakukan kalibrasi layar untuk menentukan koordinat, luas area kerja, dan luas tampilan layar.

3. Aplikasi dapat mengubah cahaya inframerah yang diterima kamera inframerah wiimote menjadi pergerakan dan fungsi-fungsi kursor pada komputer.

4. Aplikasi dapat mengelola catatan yang telah dibuat pengguna dan melakukan perbesaran pada bagian layar untuk mempermudah pengguna melakukan presentasi.

\section{3) Model Fungsional Perangkat Lunak}

Model fungsional akan disajikan dalam bentuk UML (Unified Modeling Languange) untuk memvisualisasi, menspesifikasikan, membangun, dan pendokumentasian dari sebuah pengembangan perangkat lunak berbasis OOP (Object-Oriented Programing). UML akan digambarkan dalam bentuk use case diagram, activity diagram dan sequence diagram. 


\section{a. Use Case Diagram}

Use case diagram menggambarkan fungsionalitas yang diharapkan dari aplikasi Smart Touch Presenter Kit, kebutuhan sistem dari sudut pandang pengguna serta hubungan antara actor dan use case. Use case diagram aplikasi ini ditunjukkan oleh Gambar 1.

\section{b. Activity Diagram}

Activity diagram menggambarkan proses, urutan aktivitas dalam proses-proses sistem tersebut, bagaimana setiap proses dimulai dan bagaimana suatu proses akan berakhir. Activity diagram dibuat berdasarkan sebuah atau beberapa use case pada use case diagram. Activity diagram menulis aplikasi Smart Touch Presenter Kit ditunjukkan oleh Gambar 2.

\section{c. Sequence Diagram}

Sequence diagram menggambarkan interaksi antar objek di dalam sebuah sistem. Interaksi tersebut berupa message yang digambarkan terhadap waktu. Sequence diagram dibuat berdasarkan sebuah atau use case pada use case diagram. Sequence diagram menulis aplikasi Smart Touch Presenter Kit ditunjukkan oleh Gambar 3.

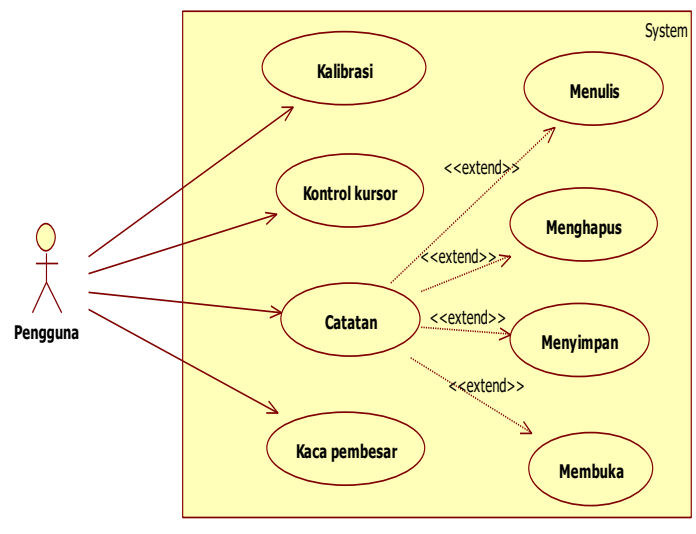

Gambar 1. Use Case Diagram Smart Touch Presenter Kit

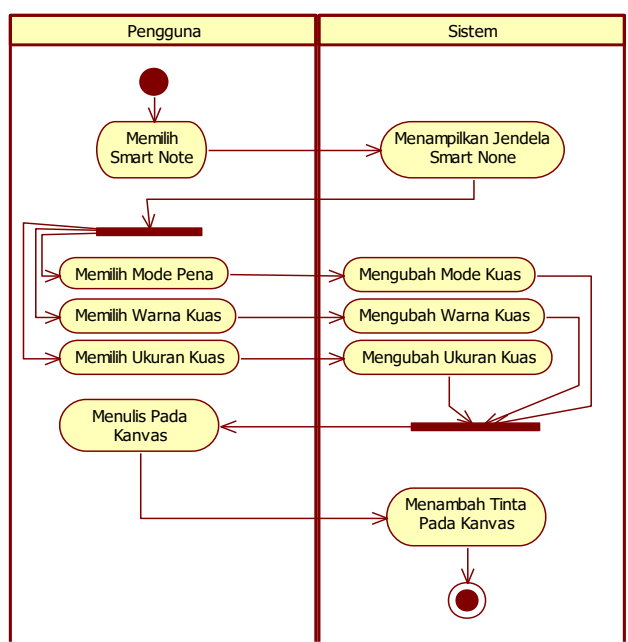

Gambar 2. Activity Diagram Menulis.

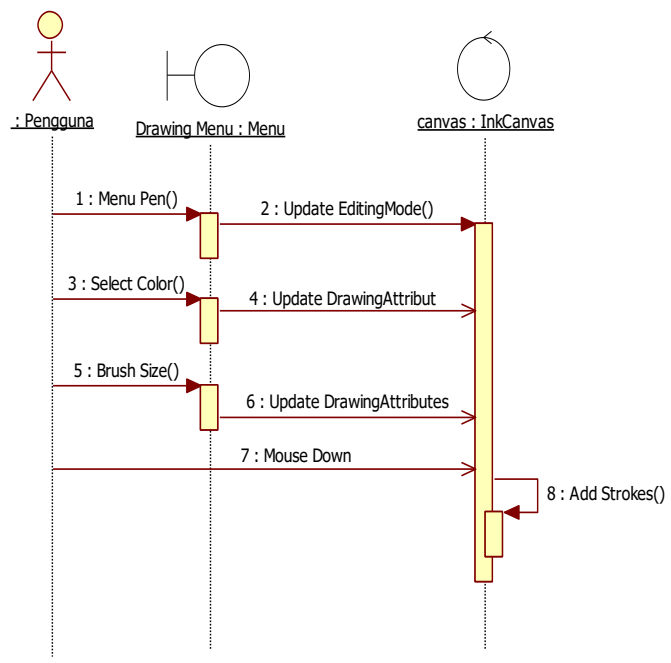

Gambar 3. Sequence Diagram Menulis

\section{Perancangan Perangkat Lunak}

Tahap perancangan perangkat lunak adalah tahap selanjutnya setelah melakukan analisis perangkat lunak. Rancangan perangkat lunak yang dibuat bersifat user friendly agar pengguna merasa nyaman dan mudah untuk menggunakannya.

\section{1) Batasan Perancangan Perangkat Lunak}

Adapun batasan perancangan perangkat lunak Smart Touch Presenter Kit dapat dipaparkan sebagai berikut. 
1. Fungsi kursor yang disediakan sistem sebagai pengganti mouse terbatas pada dua tombol utama yaitu klik kanan dan kiri.

2. aplikasi ini hanya dapat berjalan pada sistem orasi Windows dengan dukungan .Net Framework v2.0 atau yang lebih baru.

2) Perancangan Antarmuka Perangkat Lunak

Perancangan antarmuka perangkat lunak merupakan proses pembuatan antarmuka yang akan digunakan untuk berinteraksi antara pengguna dengan perangkat lunak. Rancangan yang dibuat bersifat user friendly dimana bertujuan agar pengguna merasa tertarik, nyaman, dan mudah dalam menggunakannya. Rancangan antarmuka Smart Touch Prensenter Kit dan Smart Note (catatan) ditunjukkan oleh gambar 4 dan gambar 5. Gambar 6 mrerupakan rancangan dari pena LED inframerah yang akan digunakan sebagai alat input.

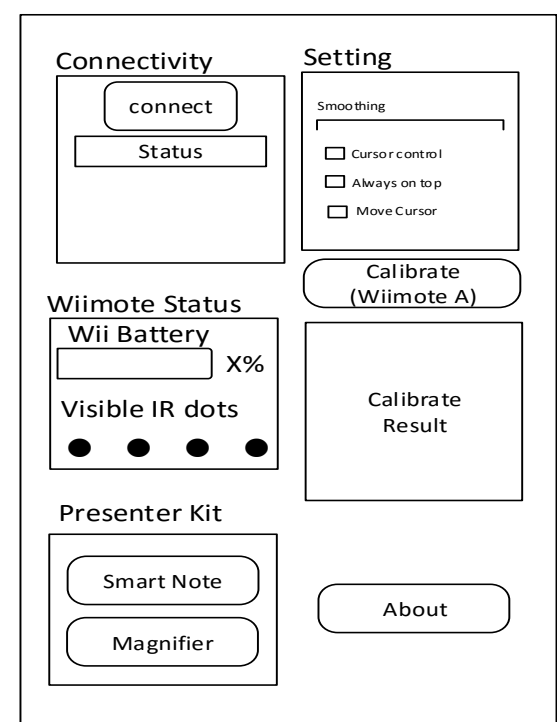

Gambar 4. Rancangan Jendela Smart Touch Presenter.

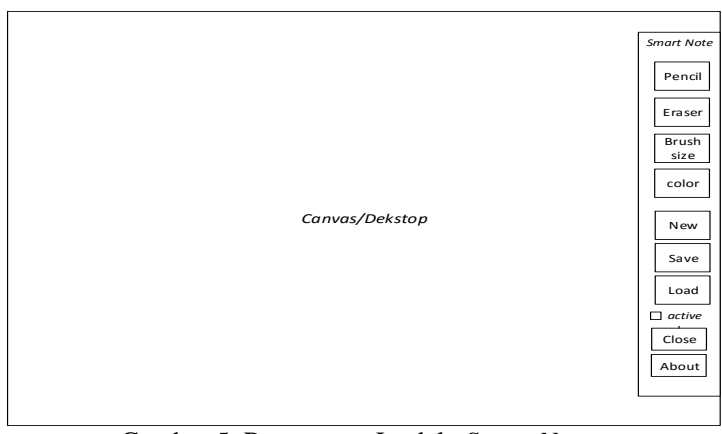

Gambar 5. Rancangan Jendela Smart Note.

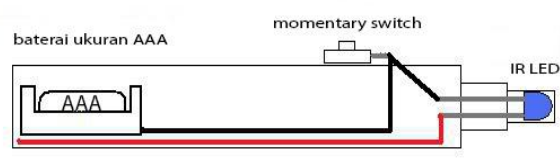

Gambar 6. Rancangan Pena LED Inframerah.

\section{PEMBAHASAN}

A. Implementasi Perangkat Lunak

Implementasi perangkat lunak Smart Touch Presenter Kit untuk presentasi interaktif terdiri dari lingkungan implementasi perangkat lunak, batasan implementasi perangkat lunak, implementasi arsitektur perangkat lunak serta implementasi layar antarmuka perangkat lunak.

\section{1) Lingkungan Implementasi Perangkat Lunak}

Pada lingkungan perangkat lunak, aplikasi dijalankan pada Sistem Operasi Windows 7 Ultimate, Visual Studio Express 2013 for Dekstop, Wiimote Library, Microsoft Office Visio 2013, Adobe Photoshop CS6, dan Advance Installer 11.0 free and 30-day trial version.

Pada lingkungan perangkat keras, aplikasi dijalankan pada Notebook ASUS N43SL, Intel ${ }^{\circledR}$ Core $^{\text {TM }}$ i5-2430M CPU @ 2.40 GHz, RAM 8.00 GB, Harddisk 750 GB, Broadcom BT-270 internal bluetooth radios dan dilengkapi dengan alat inpun dan output.

Dan pada perangkat wiji remote dengan spesifikasi Broadcom BCM 2042 bluetooth radios, PixArt Imaging $128 \times 96$ monochrome IR camera, EEPROM $16 \mathrm{~KB}$, dan Microprocessor 80116 bit.

2) Batasan Implementasi Perangkat Lunak

Batasan Batasan yang terdapat dalam implementasi perangkat lunak aplikasi Smart Touch Presenter yaitu:

1. Pada Control input hanya mendukung untuk klik kanan dan kiri mouse.

2. Aplikasi dibagi menjadi 3 buah executable file (*.exe) untuk memberikan fleksibilitas kegunaan aplikasi (Smart Note dan Magnifier dapat digunakan tanpa harus menggunakan Smart Touch Presenter) dan karena perbedaan pendekatan pemrograman dalam implementasinya (WinForm dan WPF).

3) Implementasi Layar Antarmuka Perangkat Lunak

Implemenatasi layar antarmuka perangkat lunak Tingklik \& Suling diimplementasikan menggunakan Visual Studio Express 2013 dengan 
pendekatan Winform dan WPF. Dapat dilihat pada Gambar 7 sampai dengan gambar 11. Gambar 12 menunjukkan hasil implementasi dari pena LED inframerah yang akan digunakan sebagai alat input untuk aplikasi Smart Touch Presenter Kit.
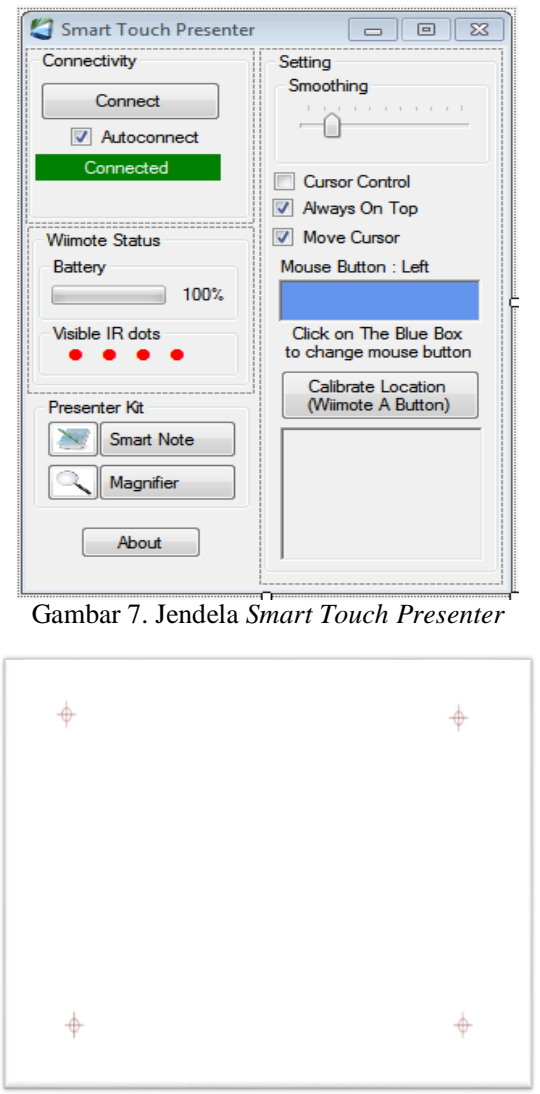

Gambar 8. Jendela Kalibrasi.

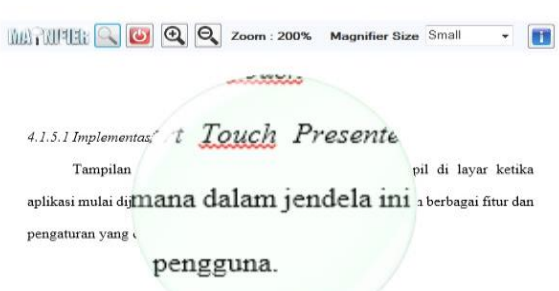

Gambar 10. Jendela Magnifier.

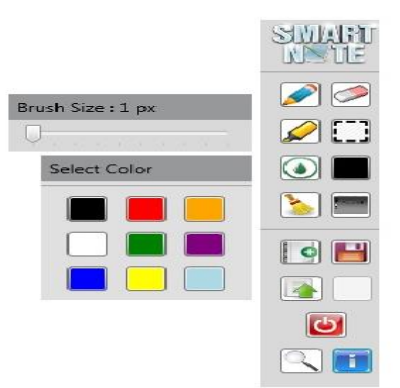

Gambar 9. Jendela Smart Note.

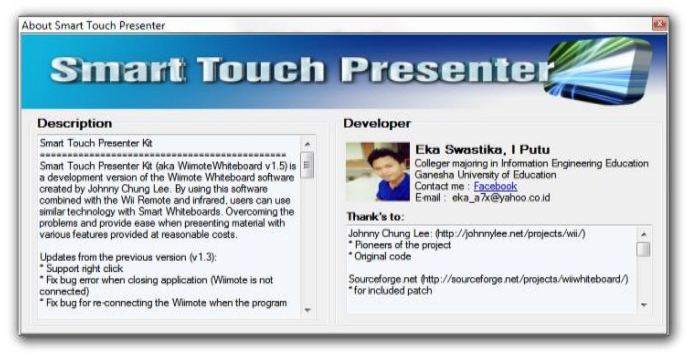

Gambar 11. Jendela About Smart Touch Presenter.

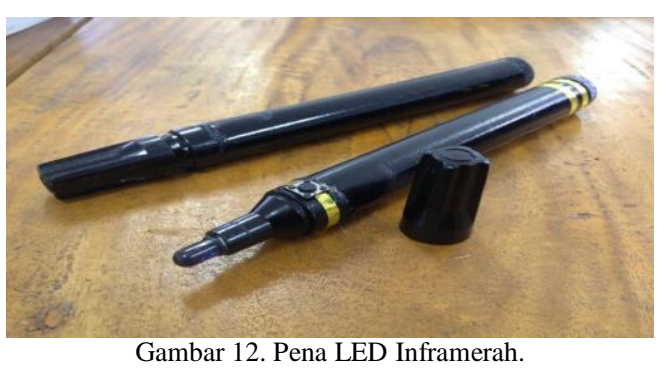

B. Pengujian Perangkat Lunak

Tahap selanjutnya setelah implementasi perangkat lunak adalah tahap pengujian perangkat lunak. Pada tahap pengujian ini akan dipaparkan mengenai tujuan pengujian perangkat lunak, pelaksanaan pengujian perangkat lunak serta evaluasi dari pengujian perangkat lunak.

\section{1) Tujuan Pengujian Perangkat Lunak}

Pengujian perangkat lunak aplikasi Smart Touch Presenter Kit dilakukan dengan mempergunakan pengujian blackbox testing. Dimana pengujian ini hanya dilihat berdasarkan keluaran yang dihasilkan dari data atau kondisi masukan yang diberikan untuk fungsi yang terdapat pada perangkat lunak tanpa melihat bagaimana proses untuk mendapatkan keluaran.

Tujuan pengujian aplikasi adalah:

1. Menguji kebenaran proses aplikasi Smart Touch Presenter Kit yang terdiri dari Smart Touch Presenter, Smart Note, dan Magnifier berdasarkan perancangan.

2. Menguji pengaturan penggunaan wiimote dengan menyesuaikan jarak dan sudut letak wiimote terhadap layar serta keadaan pencahayaan ruangan agar mengetahui pengaturan optimal sehingga cahaya inframerah dari LED inframerah dapat terdeteksi dengan baik oleh kamera inframerah wiimote.

\section{2) Pelaksanaan Pengujian Perangkat Lunak}

Pengujian perangkat lunak Smart Touch Presenter Kit dilakukan sesuai dengan kasus uji dan angket yang sudah dirancang sebelumnya. Pengujian dilakukan oleh: 1) Lima orang yang diambil secara acak, yaitu mahasiswa dari 
jurusan Pendidikan Teknik Informatika, Universitas Pendidikan Ganesha Singaraja, menggunakan beberapa perangkat komputer yang berbeda bertujuan untuk mengetahui performance dan kompabilitas dari masingmasing perangkat dalam menjalankan aplikasi Smart Touch Presenter Kit dilaksanakan pada tanggal 26 April 2014; 2) Pengembang untuk pengujian optimalisasi pengaturan penggunaan perangkat wiimote yang dilaksanakan pada tanggal 5 April 2014. Pengujian dilakukan dengan menggunakan dua jenis angket yaitu:

1. Angket kesesuaian proses Aplikasi Smart Touch Presenter Kit.

2. Angket optimalisasi pengaturan penggunaan perangkat wiimote.

\section{3) Evaluasi Hasil Pengujian Perangkat Lunak}

Melalui hasil pengujian angket kesesuaian jalannya proses aplikasi dengan berbagai perangkat komputer yang digunakan, semua proses aplikasi berfungsi dengan baik.

Berdasarkan hasil pengujian melalui angket optimalisasi pengaturan penggunaan perangkat wiimote didapat bahwa pencahayaan ruangan tidak berpengaruh signifikan terhadap hasil pendeteksian inframerah. Jarak dan sudut penempatan tidak diatur secara khusus dan dapat disesuaikan sehingga keseluruhan layar dapat dilihat oleh kamera. Hindari blocking kamera untuk menghasilkan pendeteksian yang lebih baik.

\section{SIMPULAN DAN SARAN}

Berdasarkan penelitian dan pengembangan yang telah dilakukan dapat disimpulkan.

a. Perancangan Aplikasi Smart Touch Presenter Kit telah berhasil dilakukan dengan menggunakan model fungsional berupa UML (Unified Modeling Languange) yaitu dengan menggunakan use case diagram, activity diagram, dan sequence diagram.

b. Aplikasi Smart Touch Presenter Kit telah berhasil diimplementasikan sesuai dengan rancangan yang telah dibuat sebelumnya. Aplikasi Smart Touch Presenter Kit diimplementasikan menggunakan bahasa pemrograman C\# dengan editor Visual Studio Express 2013 for Dekstop.

c. Jarak dan sudut penempatan penempatan perangkat wiimote dalam penggunaannya dapat disesuaikan dengan keadaan layar sehingga kamera dapat melihat seluruh permukaan layar dengan baik serta skala hasil kalibrasi tidak kurang dari $50 \%$.
Perangkat wiimote dapat digunakan dalam berbagai keadaan penerangan ruangan.

d. Permasalahan penggunaan sistem yaitu tidak semua perangkat bluetooth compatible dengan bluetooth perangkat wiimote, dan blocking terhadap kamera yang mengganggu proses pendeteksian inframerah.

Saran untuk pengembangan aplikasi selanjutnya adalah agar ditambahkan hal-hal seperti berikut.

a. Menambahkan fitur Smart Note Air yang memungkinkan pengguna atau peserta presentasi untuk menyimpan catatan yang dibuat oleh pemateri langsung pada perangkat komputer atau mobile mereka.

b. Menambahkan fitur multitouch untuk penggunaan lebih dari 1 pena LED inframerah secara bersamaan.

c. Dikemas dalam bentuk Smart Table atau Surface Table, meja layar sentuh yang akan memudahkan dalam proses kalibrasi dan menghasilkan pendeteksian inframerah yang lebih baik.

d. Fitur-fitur inovatif lainnya seperti Smart Screen Recorder yang memungkinkan pengguna untuk merekam, mengedit rekaman dan menyimpan hasil rekaman seluruh kegiatan presentasi.

e. Mendisain ulang Pena $L E D$ Inframerah agar menghasilkan pendeteksian yang lebih presisi, lebih mudah digunakan dan lebih mudah dalam penggantian komponen, serta mengusahakan baterai dapat di isi ulang langsung tanpa harus melepas dari pena.

\section{REFERENSI}

[1] Cohen, Nicole. 2011. Timeline: A History Of TouchScreen Technology. Terdapat pada http://www.npr.org/2011/12/23/144185699/timeline -a-history-of-touch-screen-technology. Diakses tanggal 4 Desember 2013.

[2] Lee, J.C. 2008. Hacking The Nitendo Wii Remote. Internasional : IEEE.

[3] S. Kennewell, dan A. Morgan. 2003. "Student Teachers' Experiences and Attitudes Towards Using Interactive whiteboards in The Teaching and Learning of Young Children." Swansea : Department of Education, University of Wales Swansea.

[4] S. N. Cheong, et.al. 2010. Design and Developmen of a Cost Effective Wiimote-Based Multi-Touch Teaching Solution. Selangor : Multimedia University.

[5] Yusdianto, Andre, dkk. 2011. Rancang Bangun Aplikasi Interactive Whiteboard Untuk Mendukung Pembelajaran Menggunakan Game Controlling. Surabaya: STIKOM. 